\title{
Nisbah Kelamin dan Pola Peletakan Telur Parasitoid Trichogramma chilotraeae Nagaraja \& Nagarkatti (Hymenoptera: Trichogrammatidae) pada Berbagai Jumlah Inang
}

\author{
HASRIYANTY ${ }^{1)}$, DAMAYANTI BUCHORI ${ }^{2)}$, PUDJANTO $^{2)}$ \\ 1) Jurusan Hama dan Penyakit Tanaman, Fakultas Pertanian, Universitas Tadulako Palu \\ 2) Staf Pengajar Departemen Proteksi Tanaman, Fakultas Pertanian, Institut Pertanian Bogor
}

(diterima Mei 2006, disetujui Desember 2006)

\begin{abstract}
Host Abundance and Its Effect On Sex Ratio and Oviposition Pattern of Trichogramma chilotraeae Nagaraja and Nagarkatti (Hymenoptera:Trichogrammatidae). The objective of the research was to study sex ratio and oviposition sequence of egg parasitoid Trichogramma chilotraeae in relation with host density under laboratory condition. Parasitoid response with respect to oviposition sequence was examined by exposing five different host (egg) densities: $3,6,12,24$ and 48 on female parasitoids $T$. chilotraeae. Results showed that in general, female parasitoid laid its female progeny at the beginning of oviposition sequence. Host density was found to have a strong effect on sex ratio. Sex ratio increase with increasing of host number.
\end{abstract}

KEYWORDS: Trichogramma chilotraeae, host-parasitoid, sex ratio, sequence oviposition.

\section{PENDAHULUAN}

Parasitoid famili Trichogrammatidae merupakan parasitoid yang telah banyak dikembangkan dan dimanfaatkan untuk mengendalikan berbagai jenis hama karena sifatnya yang generalis. Pemanfaatan parasitoid telur juga sering menjadi pilihan karena merupakan agens hayati yang mengendalikan hama pada fase paling awal sehingga kerusakan tanaman dapat dicegah sedini mungkin. Parasitoid ini juga mudah ditangani dan penggunaannya di lapangan dapat digabungkan dan kompatibel dengan metode pengendalian lain (Alba 1988), sehingga mendukung pelaksanaan PHT di lapangan. Famili Trichogrammatidae terutama banyak digunakan untuk menekan hama penting dari ordo Lepidoptera. Beberapa spesies Trichogramma juga dapat memarasit telur Coleoptera, Diptera, Heteroptera, Hymenoptera dan Neuroptera (Smith 1996; Knutson 2002).

Pada umumnya parasitoid Hymenoptera termasuk Trichogramma chilotraeae mempunyai pola repro- 
duksi haplodiploidi. Jantan haploid berkembang dari telur yang tidak dibuahi dan betina diploid berkembang dari telur yang dibuahi. Betina yang telah berkopulasi akan menyimpan sperma dalam spermateka, dan pada saat peletakan telur betina dapat mengatur alokasi kelamin keturunan sepanjang peletakan telur berdasarkan pada kondisi lingkungan sehingga berpengaruh pada nisbah kelamin keturunan yang dihasilkan. (Godfray 1994; Ode \& Hunter 2002).

Strategi penentuan kelamin keturunan yang dilakukan induk betina sebagai respon terhadap kondisi lingkungan, dilaporkan dilakukan melalui suatu urutan yang teratur, mempunyai pola tertentu, dan umumnya induk betina meletakkan keturunan jantan pada awal peletakan telur, sehingga biasa disebut "strategi jantan pertama" (Wanjberg 1993; Colazza \& Wajnberg 1998). Bila jumlah inang bertambah, peletakan telur yang nantinya menjadi keturunan jantan selanjutnya dilakukan pada suatu jarak yang teratur.

Parasitoid T. chilotraeae merupakan parasitoid telur yang diketahui menyerang beberapa hama Lepidoptera, termasuk Helicoverpa armigera Hubn. (Lepidoptera: Noctuidae) (Nurindah \& Bindra 1989), Chillo suppressalis (Wlk.) (Lepidoptera: Pyralidae) dan Ostrinia furnacalis (Guenee) (Lepidoptera: Pyralidae) (Kalshoven 1981), juga merupakan spesies yang relatif baru diketahui menyerang telur hama Plutella xylostella L. (Lepidoptera: Yponomeutidae) (Hasriyanty 2006). Penelitian ini bertujuan untuk mempelajari nisbah kelamin dan pola urutan peletakan telur parasitoid $T$. chilotraeae pada berbagai jumlah inang.

\section{BAHAN DAN METODE}

\section{Waktu dan Tempat}

Penelitian ini dilaksanakan pada bulan Juni 2005 sampai dengan Februari 2006, bertempat di Laboratorium Bioekologi Parasitoid dan Predator, Departemen Proteksi Tanaman, Fakultas Pertanian Institut Pertanian Bogor.

\section{Koleksi dan Perbanyakan Parasitoid serta Perbanyakan Serangga Inang Corcyra cephalonica}

Parasitoid yang digunakan pada penelitian ini berasal dari areal pertanaman kubis di daerah Pangalengan Bandung. Koleksi parasitoid dilakukan dengan cara mengumpulkan kelompok-kelompok telur Plutella xylostella yang ada pada daun kubis menggunakan tangan (hand picking method). Telur yang terkumpul dibawa ke laboratorium dan diinkubasikan sampai parasitoid muncul dari telur yang terparasit. Parasitoid kemudian dikembangbiakkan pada telur inang pengganti Corcyra cephalonica Stointon (Lepidoptera: Pyralidae). Parasitoid dari perbanyakan ini 
kemudian dibiakkan lebih lanjut sebagai bahan penelitian.

Perbanyakan parasitoid dilakukan dengan cara menempelkan telur C. cephalonica menggunakan gom arabik pada suatu pias (potongan karton yang berukuran $1 \times 4 \mathrm{~cm}$ ). Telur inang yang ada pada pias kemudian disimpan pada suhu $0^{\circ} \mathrm{C}$ selama dua jam dengan tujuan untuk membunuh embrio dalam telur. Pias selanjutnya dimasukkan dalam tabung reaksi untuk dipaparkan pada parasitoid.

Perbanyakan inang pengganti C. cephalonica dilakukan dengan cara menempatkan imago jantan dan betina pada suatu tabung pembiakan berbentuk silinder dengan bagian tutup atas dan bawah terbuat dari kawat kasa 25 mesh, sebagai tempat imago betina nantinya meletakkan telur. Tabung selanjutnya ditempatkan pada kurungan kasa. Setiap hari telur yang dihasilkan dipanen. Sebagian telur digunakan untuk bahan penelitian, sebagian lagi digunakan untuk perbanyakan parasitoid dan sebagian lainnya untuk perbanyakan C. cephalonica sendiri dengan cara menaburkan telur pada wadah yang berisi campuran dedak dan pakan ayam.

\section{Studi Nisbah Kelamin dan Pola Urutan Peletakan Telur}

Parasitoid yang digunakan pada percobaan ini adalah parasitoid yang telah berumur satu hari dan telah berkopulasi serta telah diberi makan cairan madu $10 \%$. Pias dibuat dengan cara merekatkan telur inang yang jumlahnya disesuaikan dengan perlakuan, yakni $3,6,12,24$ dan 48 telur tiap pias. Telur direkatkan satu per satu dan disusun dalam barisanbarisan. Pias kemudian dimasukkan ke dalam tabung reaksi yang sudah berisi parasitoid dan selanjutnya diamati di bawah mikroskop. Untuk mencatat setiap urutan telur inang yang diparasit, terlebih dahulu dibuat skema pada selembar kertas yang menggambarkan posisi yang sama dengan barisan-barisan telur yang ada pada pias. Pada skema inilah dicatat atau diberi kode dari setiap urutan pemarasitan yang diamati. Selama pengamatan berlangsung, betina yang akan melakukan superparasitisme (mendatangi inang yang sebelumnya sudah diparasit) dicegah dengan cara menghalau betina tersebut dengan menggunakan kuas halus.

Setelah semua telur inang terparasit atau pemarasitan telah berlangsung selama tiga jam pada kelompok inang yang banyak, pias dikeluarkan dari dalam tabung. Telur inang yang sudah diparasit kemudian dipisahkan satu persatu menggunakan cutter dan selanjutnya dimasukkan ke dalam microtube berukuran $1,5 \times 10$ $\mathrm{cm}$ dan diberi kode. Imago parasitoid yang keluar kemudian diamati di bawah mikroskop untuk mengetahui jenis kelamin keturunan pada setiap urutan peletakan telur. 
Percobaan disusun dalam kelamin (proporsi betina) yang rancangan acak lengkap (RAL) dengan dihasilkan dianalisis dengan ANOVA lima perlakuan jumlah inang yakni 3, dan dilajutkan dengan uji Tukey pada 6, 12, 24 dan 48 inang. Setiap $\alpha 0,05$. Data diolah menggunakan perlakuan jumlah inang dilaksanakan program Minitab.

dalam 20 ulangan sehingga terdapat 200 unit perlakuan.

Data jenis kelamin keturunan yang dihasilkan pada setiap urutan peletakan telur dianalisis secara deskriptif, diambil dari ciata persentase betina selama urutan peletakan telur. Data dianalisis lebih lanjut, dilakukan dengan menggunakan metode nonparametrik, uji Kruskal Wallis Test dan dilanjutkan dengan uji Sign test dan uji Wilcoxon signed rank test. Data nisbah

\section{HASIL DAN PEMBAHASAN}

\section{Hasil}

Nisbah kelamin keturunan yang dihasilkan induk betina $T$. chilotraeae dipengaruhi oleh jumlah inang $(P=$ 0.000) (Gambar 1). Rata-rata nisbah kelamin akan meningkat seiring bertambahnya inang, yakni dari 0,61 pada perlakuan tiga inang menjadi 0,77 pada perlakuan 48 inang. Hasil

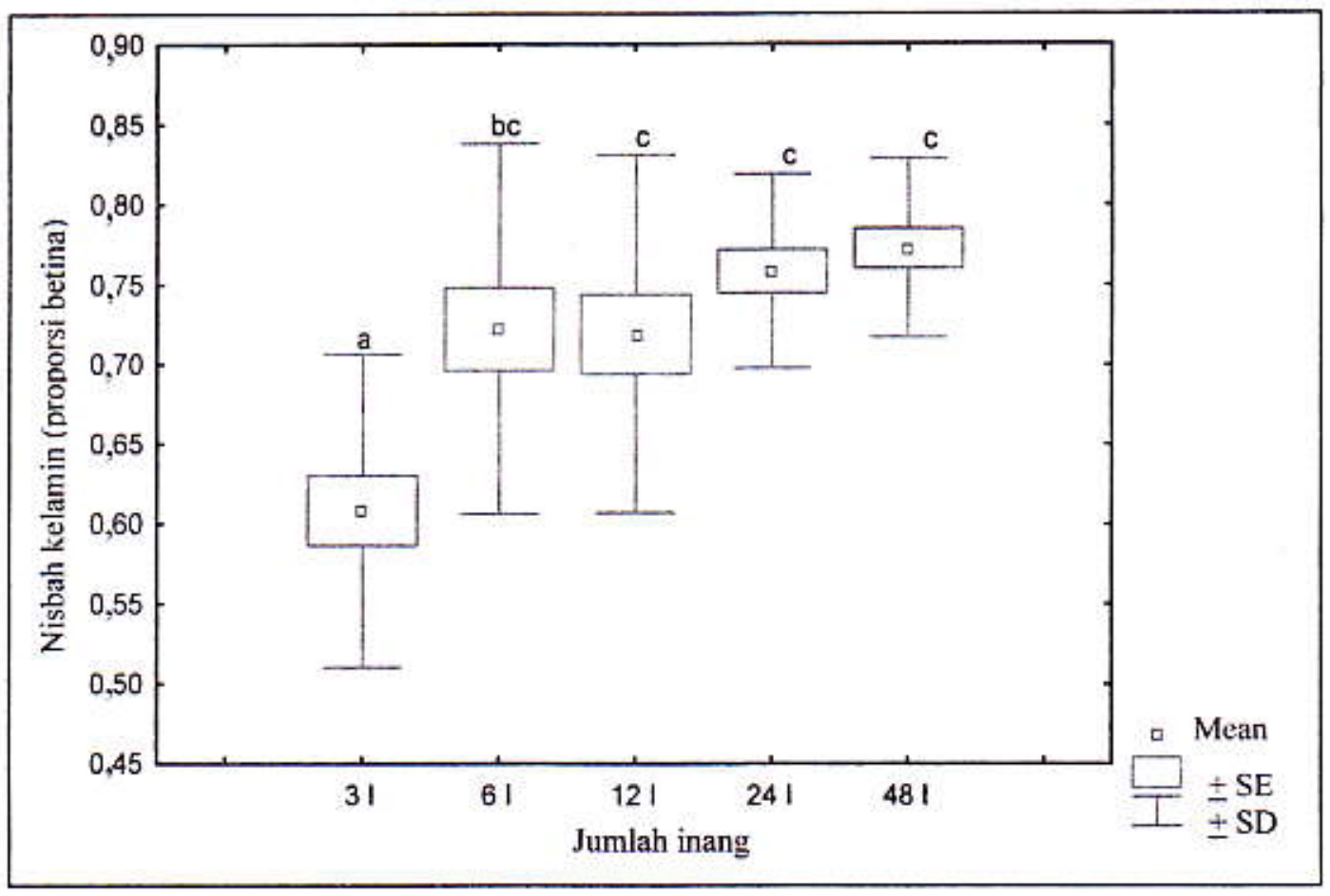

Gambar 1. Nisbah kelamin keturunan yang dihasilkan induk betina yang meletakkan telur pada berbagai kepadatan inang 
analisis menunjukkan bahwa nisbah kelamin pada tiga inang berbeda dengan semua perlakuan jumlah inang lainnya, sedangkan di antara perlakuan kepadatan inang $6,12,24$ dan 48 , nisbah kelamin tidak berbeda nyata. Persentase keturunan betina yang dihasilkan sepanjang rangkaian peletakan telur pada berbagai perlakuan jumlah inang ditampilkan pada Gambar 2, menunjukkan bahwa induk betina memberikan respon yang berbeda terhadap berbagai perlakuan jumlah inang, tetapi pada umumnya menghasilkan keturunan betina pada awal peletakan telur. Alokasi kelamin
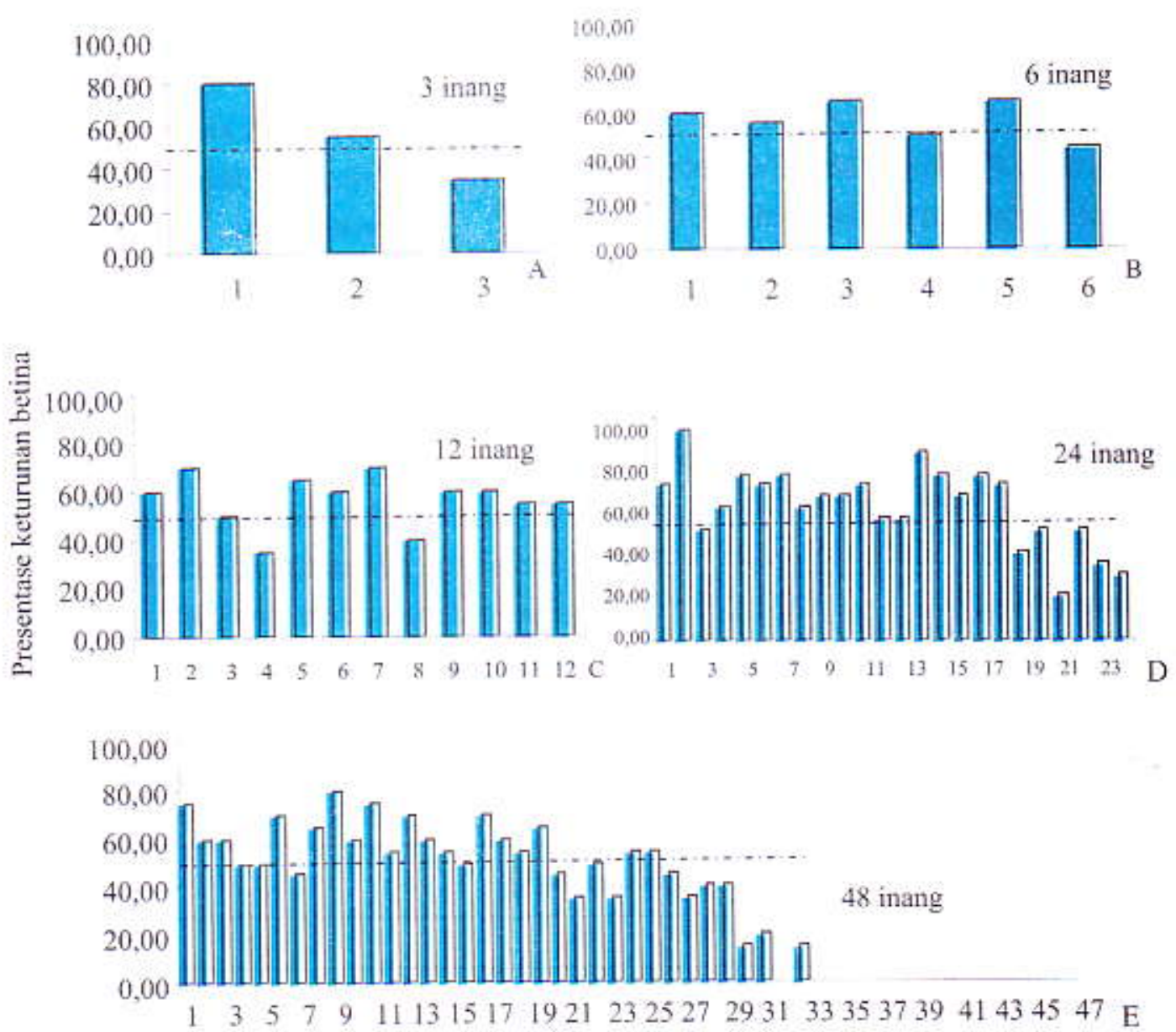

Urutan peletakan telur

Gambar 2. Persentase keturunan betina yang dihasilkan pada setiap urutan peletakan telur pada berbagai kepadatan inang, pemaparan satu parasitoid betina. ( $----=50 \%$ keturunan betina). 
keturunan yang dihasilkan induk betina pada setiap urutan peletakan telur dilihat secara keseluruhan mulai dari peletakan telur ke-1 sampai ke-n menunjukkan bahwa jumlah keturunan betina yang dihasilkan induk parasitoid cenderung akan semakin berkurang dari peletakan telur pertama sampai peletakan telur keempat, kemudian kembali meningkat pada peletakan telur kelima. Pada akhir rangkaian peletakan telur, keturunan betina yang dihasilkan cenderung menurun (Tabel 1). Akan tetapi, berdasarkan hasil pengujian Kruskal-Wallis Test ternyata bahwa perlakuan jumlah inang $3,6,12$, 24 dan 48 tidak berpengaruh nyata terhadap rasio kelamin keturunan betina-jantan pada setiap urutan peletakan telur $(P=0.403)$. Uji lanjut dengan Sign test dan Wilcoxon signed rank test, memberikan hasil yang signifikan $P=0.000$ terhadap nisbah kelamin $50: 50$.

\section{Pembahasan}

Gambar 1 menunjukkan bahwa nisbah kelamin akan meningkat seiring bertambahnya jumlah inang. Hal ini sejalan dengan yang dikemukakan Wajnberg (1994) bahwa umumnya pada parasitoid Trichogramma, nisbah kelamin akan bias betina bila jumlah inang bertambah. Kecenderungan terjadinya peningkatan nisbah kelamin bila inang yang dipaparkan bertambah, juga terjadi pada parasitoid Telenomus busseolae Gahan (Hymenoptera: Scelionidae) (Bayram et al. 2004) dan parasitoid Trisolcus basalis (Wollaston) (Hymenoptera: Scelionidae) (Collazza \& Wajnberg 1998).

Bila dilihat dari strategi pengaturan alokasi kelamin keturunan oleh induk betina, dapat dikatakan bahwa induk betina parasitoid $T$. chilotraeae ini memberikan respon yang berbeda terhadap perlakuan berbagai jumlah inang dengan cara mengatur peletakan keturunan betina atau jantan sepanjang peletakan telur, akan tetapi pada

Tabel 1. Alokasi jenis kelamin keturunan yang dihasilkan induk parasitoid $T$. chilotraeae pada peletakan telur ke-1 sampai peletakan telur ke-n

\begin{tabular}{|c|c|c|c|c|c|c|c|c|c|c|c|c|c|c|}
\hline \multirow{3}{*}{ Perlakuan } & \multicolumn{13}{|c|}{ Peletakan telur ke } & \multirow{3}{*}{$\begin{array}{l}\text { Nilai } \\
\text { tengah } \\
\text { selisih } \\
\text { betina- } \\
\text { jantan }\end{array}$} \\
\hline & \multicolumn{2}{|c|}{1} & \multicolumn{2}{|c|}{2} & \multicolumn{2}{|c|}{3} & \multicolumn{2}{|c|}{4} & \multicolumn{2}{|c|}{5} & \multicolumn{3}{|c|}{$\ldots \mathrm{n}$} & \\
\hline & q & $\delta$ & 9 & 8 & 9 & 8 & ? & 8 & 웅 & 8 & & q & 8 & \\
\hline 3 inang & 16 & 4 & 11 & 7 & 7 & 10 & & & & & $(n: 3)$ & & & 4 \\
\hline 6 inang & 13 & 2 & 12 & 6 & 13 & 5 & 10 & 6 & 13 & 3 & (n: 6) & 10 & 3 & 7.5 \\
\hline 12 inang & 12 & 3 & 17 & 0 & 10 & 7 & 7 & 8 & 14 & 4 & $(n: 12)$ & 11 & 4 & 7,5 \\
\hline 24 inang & 14 & 2 & 19 & 0 & 10 & 5 & 12 & 6 & 16 & 3 & $(\mathrm{n}: 24)$ & 6 & 5 & 9.5 \\
\hline 48 inang & 15 & 0 & 12 & 3 & 12 & 2 & 10 & 7 & 10 & 2 & $(n: 36)$ & 0 & 2 & 7 \\
\hline Total & 70 & 11 & 71 & 16 & 52 & 29 & 39 & 27 & 53 & 12 & & 27 & 14 & \\
\hline$N$ & \multicolumn{2}{|c|}{81} & \multicolumn{2}{|c|}{87} & \multicolumn{2}{|c|}{81} & \multicolumn{2}{|c|}{66} & \multicolumn{2}{|c|}{65} & \multicolumn{4}{|c|}{41} \\
\hline
\end{tabular}

Ket: $\mathrm{n}=$ peletakan telur terakhir 
umumnya akan meletakkan keturunan betina pada awal peletakan telur (Gambar 2). Kecenderungan peletakan keturunan betina pada awal-awal peletakan telur pada parasitoid $T$. chilotraeae ini berbeda bila dibandingkan dengan beberapa parasitoid Hymenoptera lainnya, dilaporkan memulai rangkaian peletakan telur dengan meletakkan keturunan jantan pada awal peletakan telur. Hasil penelitian Wajnberg menunjukkan bahwa parasitoid Trichogramma brassicae Bezdenco, akan memulai rangkaian peletakan telur dengan meletakkan keturunan jantan pada awal rangkaian peletakan telur. Demikian pula hasil penelitian Collazza \& Wajnberg (1998), pada parasitoid $T$. basalis yang menunjukkan bahwa urutan peletakan telur pada berbagai jumlah inang dalam satu paket tidak diletakkan secara acak. Peletakan telur pertama pada semua perlakuan berbagai jumlah inang selalu jantan "male first strategy".

Berdasarkan hasil tersebut, dapat dikatakan bahwa parasitoid $T$. chilotraeae mempunyai kemampuan untuk mengukur jumlah inang yang ada dan meresponnya dengan mengubah alokasi keturunan betina atau jantan sepanjang peletakan telur. Kemampuan parasitoid untuk menaksir jumlah inang sesaat sebelum melakukan peletakan telur dan mengatur alokasi kelamin keturunan pada suatu pola tertentu, kemungkinan disebabkan oleh beberapa petunjuk fisik yang telah diterima oleh parasitoid. Parasitoid yang mengeksploitasi suatu kelompok inang mempunyai kemampuan untuk mendapatkan informasi dengan cara berjalan dan mengetukkan antenanya pada atau dekat pinggiran suatu kelompok inang sebelum melakukan peletakan telur pertama (Colazza \& Wajnberg 1998). Selain itu, adanya petunjuk kimia yang dihasilkan oleh inang juga dapat dijadikan petunjuk oleh parasitoid untuk mengukur jumlah inang (Bayram et al. 2004). Mekanisme pertama kemungkinan yang digunakan oleh parasitoid $T$. chilotraeae ini. Hal ini didasarkan pada pengamatan bahwa parasitoid mempunyai perilaku berjalan cepat secara acak melewati beberapa inang sambil mengetuk-ketukkan antenanya sebelum menetapkan pilihan pada salah satu inang. Perilaku ini kemungkinan merupakan cara parasitoid untuk mendapatkan informasi tersebut.

Meskipun demikian, berdasarkan hasil pengujian menggunakan metode Kruskal-Wallis Test ternyata bahwa perlakuan jumlah inang tidak berpengaruh nyata terhadap rasio kelamin keturunan betina-jantan pada setiap urutan peletakan telur (Tabel 1). Uji lanjut dengan Sign test dan Wilcoxon signed rank test bahwa perbandingan kelamin keturunan (betina : jantan) bukan 50 : 50 yang 
berarti menunjukkan bahwa pada dasarnya alokasi kelamin keturunan pada parasitoid $T$. chilotraeae ini tidak sejalan dengan prediksi menurut teori Fisher yang menyatakan bahwa setiap betina pada suatu populasi akan menghasilkan keturunan betina dan jantan dengan proporsi yang sama.

Pada perlakuan tiga inang, menurunnya proporsi betina dapat terjadi karena beberapa hal. Pertama adalah ketiadaan sperma atau kedua karena memang hal ini merupakan pilihan parasitoid, yang berarti seekor induk betina dengan sengaja meletakkan keturunan jantan pada peletakan tersebut. Mekanisme kedua tampaknya lebih berperan dibanding mekanisme pertama. Hal ini disebabkan pada peletakan telur pertama dan peletakan telur kedua, induk parasitoid lebih memilih meletakkan keturunan betina dibandingkan keturunan jantan. Akibatnya, pada peletakan telur pada inang terakhir keturunan jantan lebih banyak. Sebaliknya, pada keadaan jumlah inang yang banyak, akan memberikan peluang yang lebih banyak pada induk betina untuk meletakkan telur, sehingga peletakan keturunan jantan tidak dilakukan pada peletakan telur tertentu. Hasil ini memberikan implikasi penting pada kegiatan pelepasan parasitoid di lapangan. Jika kondisi inang di lapangan rendah dan bila peletakan telur terakhir bias jantan, maka hal ini akan memberikan implikasi tertentu pada perkembangan populasi parasitoid.

Menurunnya proporsi betina pada akhir rangkaian peletakan telur pada perlakuan 24 dan 48 inang (juga digambarkan pada Gambar 2 D dan 2 E), ternyata disebabkan karena rendahnya jumlah inang terparasit pada akhir rangkaian peletakan telur, yakni hanya terdapat 11 inang terparasit pada perlakuan 24 inang dan 2 inang terparasit pada perlakuan 48 inang. Rendahnya inang terparasit pada akhir rangkaian peletakan telur karena beberapa parasitoid sudah tidak memarasit lagi. Hal ini menunjukkan bahwa terdapat suatu kisaran optimum jumlah inang yang dapat diparasit oleh parasitoid $T$. chilotraeae ini dalam jangka waktu tiga jam.

Secara umum bahwa pengamatan perilaku reproduksi bertujuan untuk lebih memahami perilaku apa yang dilakukan parasitoid untuk tujuan memaksimalkan keberhasilan reproduksi dan keberlangsungan keturunannya, yang secara langsung memberikan arti penting untuk memperbaiki keefektifan pengendalian hama sasaran di lapangan dalam suatu program pengendalian hayati.

\section{KESIMPULAN}

Jumlah inang berpengaruh terhadap nisbah kelamin keturunan yang dihasilkan, nisbah kelamin semakin meningkat seiring bertambahnya jumlah inang. 
Pada umumnya parasitoid $T$. chilotraeae memulai rangkaian peletakan telur dengan meletakkan keturunan betina pada awal-awal peletakan telur.

\section{DAFTAR PUSTAKA}

Alba MC. 1988. Trichogrammatids in the Philipines. Philipp. Ent 7(3): 253-271.

Bayram A, Salerno G, Conti E, Wajnberg E, Bin F, Kornosor S. 2004. Sex allocation in Telenomus busseolae, a solitary parasitoid of concealed eggs: the influence of host patch size. $J$ Entomologia Experimentalis et Applicata 111: 141-149.

Colazza S, Wajnberg E. 1998. Effect of host egg mass size on sex ratio and oviposition sequence of Trissolcus basalis (Hymenoptera : Scelionidae). $J$ Population Ecology 27: 329-336.

Godfray HCJ. 1994. Parasitoids : Behavioral and Evolutionary Ecology. New Jersey: Princenton University Press.

Hasriyanty, 2006. Perilaku, pola peletakan telur dan efisiensi pemarasitan parasitoid Trichogramma chilotreaeae Nagaraja \& Nagarkatti (Hymenoptera: Trichogrammatidae) pada berbagai jumlah inang dan kepadatan parasitoid [Tesis]. Bogor: Sekolah Pasca sarjana Institut Pertanian Bogor.

Kalshoven LGE. 1981. The Pests of Crops In Indonesia. Laan PA van der, penerjemah. Jakarta: CV. Ichtiar Baru Van-Hoeve.

Knutson A. 2002. The Trichogrmma Manual. The Texas Agricultural Extention Service. File://A:ITrichogrammalThe Trichogramma Manual.htm [2] Juni 2005].

Nurindah, Bindra OS. 1989. Studies on Trichogramma spp. (Hymenoptera : Trichogrammatidae) in the control of Heliothis armigera (Hubner) (Lepidoptera: Noctuidae). Biotrop. Spec. Publ. 36: 165-173.

Ode PJ, Hunter MS. 2002. Sex ratios of parasitic hymenoptera with unusual lifehistories in science. Di dalam: Hardy ICW, editor. Sex Ratio, Consepts and Research Methods. Cambridge: Cambridge University Press.

Smith SM. 1996. Biological control with trichogramma : advances, successes and potential of their use. $J$ Ann. Rev. Entomol 41 : 375-406.

Wajnberg 1993. Genetic variation in sex allocation in parasitic wasp: variation in sex pattern with sequence of oviposition. $J$ Entomologia Experimentalis et Applicata [Abstrac]. CD-ROM, CAB International.

Wajnberg E. 1994. Intra population genetic variation in Trichogramma. Di dalam: Wajnberg E, Hassan SA, editor. Biological Control With Egg Parasitoids. Wallingford: $\mathrm{CAB}$ International. 